\title{
EL CONVENIO DEL AGUA DE LA UNECE: ¿UN INSTRUMENTO COMPATIBLE CON LA CONVENCIÓN DE 1997 PARA REGULAR LOS USOS DEL AGUA DULCE INTERNACIONAL? UN ANÁLISIS COMPARADO
}

Alejandro Pastori Fillol (*)

\begin{abstract}
RESUMEN. El presente trabajo es un estudio comparado práctico y aplicado de un aspecto genérico destacado tanto en el preámbulo de la Declaración Universal de Derechos Humanos, como en su texto, esto es la cooperación para el desarrollo entre los Estados y el derecho a una condición de vida digna del ser humano. Al respecto la gestión del agua dulce internacional y la sostenibilidad ambiental de la misma pasa a ser un aspecto de gran trascendencia, que probablemente tenga cada vez mayor incidencia en los años venideros. En este entendido se analizan aquí los principales aspectos de las dos convenciones internacionales, el Convenio de Agua de 1992 y la Convención de 1997 que regulan los usos de los cursos de agua internacionales para fines distintos de la navegación. En la medida de esa coincidencia, parece necesario precisar las diferencias que tienen entre sí, máxime cuando ambas están en vigor y abiertas a la ratificación o adhesión de más Estados. A estos efectos, tomaremos como base el Convenio del Agua (que fue el último de los dos en internacionalizarse y contiene normas más detalladas) y haremos el análisis de sus principales disposiciones observando en qué medida se apartan o se compatibilizan con las previsiones de la Convención de 1997, para concluir sobre este aspecto y sus consecuencias en función de lo evaluado.
\end{abstract}

PALABRAS CLAVES. Agua dulce internacional. Convenio del Agua de la UNECE. Cooperación; Desarrollo sostenible.

*Doctor en Derecho y Ciencias Sociales (UDELAR). Doctor en Derecho de la Universidad de Valencia (España) con tesis en Derecho Internacional Público. Catedrático de Derecho Internacional Público de la Facultad de Derecho de la UDELAR. Correo electrónico: alejandropastori@adinet.com.uy. 


\begin{abstract}
The present work is a practical and applied comparative study of a generic aspect highlighted both in the preamble of the Universal Declaration of Human Rights, and in its text, this is cooperation for development among States and the right to a living condition with human dignity. In this regard, the management of international fresh water and environmental sustainability becomes an aspect of great importance, that will have an increasing incidence in future years. In this understanding, the main aspects of the two main international conventions, the 1992 Water Convention and the 1997 Convention that regulate both the uses of international watercourses for purposes other than navigation, are analyzed here. To the extent of this coincidence, it seems necessary to specify the differences between them, especially when both are in force and open to the ratification or accession of more States. We will take as a basis the Water Convention (which was the last of the two to be internationalized and contains more detailed rules) and we will analyze its main provisions, observing the extent to which they diverge or are compatible with the provisions of the Convention of 1997, to conclude on this aspect and its consequences.
\end{abstract}

KEY WORDS. International fresh water. Cooperation. UNECE. Water Convention. Sustainable development

\title{
INTRODUCCIÓN
}

El manejo habitual en nuestros cursos de Derecho Internacional Público (y en varios manuales) de la Convención de las Naciones Unidas sobre el Derecho de los Usos de los Cursos de Agua Internacionales con Fines Distintos de la Navegación, del 21 de mayo de 1997 (en adelante "la Convención de 1997"), como el instrumento multilateral "madre" en la materia, ha generado en muchos internacionalistas el convencimiento (en el que me incluía hasta hace poco) de que era el único texto sobre el tema con carácter verdaderamente internacional.

Esto sin embargo es un error dado que en 1992, la Comisión Económica para Europa de las Naciones Unidas (UNECE, por sus siglas en inglés) adoptó el Convenio sobre la Protección y Utilización de los Cursos de Agua Transfronterizos y de los Lagos Internacionales (en adelante "Convenio del Agua”), el cual entró en vigor para los países europeos en 1996, y fue abierto a la adhesión de países del resto del mundo en el 2013, tras una enmienda a tales efectos que se le realizara en el $2003^{1}$. A la fecha el Convenio del Agua de la UNECE tiene 42 Estados Partes ${ }^{2}$ y es por tanto otro texto internacional que regula los usos de los cursos de agua internacionales, al igual que la Convención de $1997^{3}$

${ }^{1}$ Nótese además que en realidad el Convenio del Agua de 1992 fue anterior a la Convención de 1997, pero que recién se internacionalizó, y por tanto igualó en ese aspecto a la Convención, en el 2013.

2 Ver: http://www.unece.org/env/water/, consultado el 22/08/2018.

${ }^{3}$ El Convenio del Agua contiene 32 artículos y 13 anexos. Ha servido de modelo para varios acuerdos de cooperación transfronteriza, que aplican sus disposiciones en contextos subregionales específicos. Uno de los primeros ejemplos es el Convenio para la Protección del Río Danubio (1994), a los que se suman otros, como son los acuerdos sobre el Lago Peipsi y los ríos Sava, Bug, Meuse, Rhin y Scheldt. Los cinco 
Esta duplicación de textos internacionales amerita los comentarios de este artículo, a los efectos de analizar la compatibilidad entre ambos textos o bien las diferencias que existen entre ellos que pueden tener consecuencias a la hora de decidir a un Estado a formar parte de uno de ellos, de ambos, o de ninguno.

Cabe destacar que el presente trabajo es un estudio comparado de un aspecto destacado en el preámbulo de la Declaración Universal de Derechos Humanos - esto es el desarrollo de relaciones amistosas entre los Estados mediante la cooperación entre los mismos- , elcual se complementa con el propósito enunciado luego en el articulado de ese texto de lograr una condición de vida digna para el ser humano. Por lo cual el tema de la gestión del agua dulce internacional y la sostenibilidad ambiental de la misma pasa a ser un aspecto de gran trascendencia, relacionado con un aspecto de los Derechos Humanos que probablemente tenga cada vez mayor incidencia en los años futuros como desarrollo de la propia Declaración.

Para realizar el análisis, seguiremos la siguiente secuencia que nos permitirá referirnos comparativamente a los aspectos esenciales de ambos tratados, sistematizando sus contenidos de la siguiente forma: (1) ámbito de aplicación, (2) principios generales sustantivos contemplados, (3) normas institucionales y (4) solución de controversias. A esto seguirán las conclusiones que se extraen del análisis realizado.

\section{AMBITO DE APLICACIÓN.}

El primer párrafo del preámbulo del Convenio del Agua deja ya sentados elementos centrales para la definición posterior del ámbito de aplicación del mismo, a saber, que su objeto será la "protección y utilización de los cursos de agua transfronterizos y de los lagos internacionales", que "sólo se puede lograr mediante una cooperación más estrecha".

Siempre dentro del objetivo acotado de señalar matices o diferencias en la comparación con la Convención de 1997, realizaremos en este punto las siguientes consideraciones:

\subsection{Espacial}

El artículo I.1 define las "aguas transfronterizas" como "todas las aguas superficiales o subterráneas que marcan, atraviesan o están situadas en las fronteras entre dos o más Estados; por lo que respecta a las aguas transfronterizas que desembocan directamente en el mar, su límite lo constituye una línea recta imaginaria trazada a través de la desembocadura entre los dos puntos extremos de las orillas durante la bajamar."

No caben dudas por tanto que las aguas subterráneas -incluidas las que se encuentran en acuíferos confinados- están comprendidas en el ámbito de aplicación del Convenio del

\footnotetext{
países que comparten el Río Tisza -Eslovaquia, Hungría, Rumania, Serbia y Ucrania- desarrollan una rica cooperación, logrando una gestión integrada de la cuenca. Luego de la disolución de la Unión Soviética y de Yugoslavia, el Convenio prestó gran utilidad como referencia para nuevos acuerdos sobre aguas que antes eran gestionadas a nivel nacional. Asimismo, el Convenio del Agua inspiró los principios y enfoques de la Directiva Marco del Agua de la UE, influenció el trabajo de varios órganos conjuntos y promovió el establecimiento de nuevo órganos, tales como comisiones para los ríos Elba, Danubio, Meuse, Oder y Scheldt, y los lagos Ginebra, Ohrid y Peipsi. (ver Mariana Beaugé, en bibliografía)
} 
Agua. En cambio, la Convención de 1997, al definir al curso de agua como "un sistema de aguas de superficie y subterráneas que, en virtud de su relación física, constituyen un conjunto unitario y normalmente fluyen a una desembocadura común", dejó fuera de su alcance los acuíferos no vinculados a un curso de agua internacional y que no fluyen normalmente a una desembocadura común o, en otras palabras, a las "aguas subterráneas confinadas" ${ }^{4}$ El Convenio del Agua no requiere que las aguas subterráneas constituyan un "conjunto unitario" con las aguas de superficie, por lo que es unánime aquí la interpretación en el sentido de que quedan comprendidas dentro de su ámbito de aplicación, las aguas subterráneas confinadas.

En otro orden, cabe señalar que el Convenio del Agua promueve la implementación de la gestión integrada de recursos hídricos con un fuerte enfoque en la gestión organizada a nivel de cuencas. ${ }^{5}$ Esto ya se hace evidente en la redacción del mismo preámbulo, ${ }^{6}$ y se confirma, como veremos inmediatamente, en la definición de "impacto transfronterizo", su ordenación y la cooperación al respecto, previstas en los artículos 1, 2 y 9 del Convenio.

Recordemos que éste no era el caso de la Convención de 1997, cuyo ámbito de aplicación no era la cuenca hidrográfica en sí misma -que se define como un área geográfica ${ }^{7}$ - sino únicamente el curso de agua, definido como el sistema de aguas de superficie y subterráneas que, en virtud de su relación física, constituye un conjunto unitario y normalmente fluye a una desembocadura común, más allá de las disposiciones sobre protección ambiental al curso de agua que allí se establecen (Parte IV de la Convención).

Como indicáramos supra, los artículos 1, 2 y 9 del Convenio confirman nuestra interpretación en el sentido de que su ámbito de aplicación espacial es toda la cuenca hidrográfica definida como un área geográfica. En efecto, el artículo 2 establece que "Las Partes adoptarán todas las medidas apropiadas para prevenir, controlar y reducir todo impacto transfronterizo. "Y el artículo 1 -titulado Definiciones- define el impacto transfronterizo en su numeral 2 de la siguiente manera:

"Por 'impacto transfronterizo' se entiende todo efecto adverso importante que una modificación del estado de las aguas transfronterizas causada por una actividad humana, cuyo origen físico se sitúe total o parcialmente en una zona bajo la jurisdicción de una Parte, pueda producir sobre el medio ambiente de una zona

${ }^{4}$ Esta es la opinión mayoritaria, pero no es ésta la interpretación de todos. Por ejemplo AttilaTanzi entiende que una interpretación contextual de la Convención de 1997 permite apoyar la tesis de que sus reglas también se podrían aplican a las aguas subterráneas confinadas. En:Tanzi, Attila, The Relationship between the 1992 UNECE Convention on the Protection and Use of Transboundary Watercourses and International Lakes and the 1997 UN Convention on the Law of the Non-Navigational Uses of International Watercourses, Report of the UNECE Task Force on Legal and Administrative Aspects, Pág. 8.

${ }^{5}$ Comisión Económica para Europa de las Naciones Unidas (UNECE), Apertura Global del Convenio del Agua de 1992, En: http://www.unwater.org/app/uploads/2017/05/Brochure_ECE_SPA_PDF_WEB.pdf consultado el 27/08/18

${ }^{6}$ Que incluye, para citar algún ejemplo, referencias a "hacer disminuir la eutrofización y la acidificación, así como la contaminación del medio marino desde fuentes terrestres."

${ }^{7}$ Como lo indican las conocidas Reglas de Helsinki en la materia: "una cuenca hidrográfica internacional es la zona geográfica que se extiende por el territorio de dos o más Estados determinada por la línea divisoria de un sistema hidrográfico de aguas superficiales y freáticas que fluyen hacia una salida común." 
bajo la jurisdicción de otra Parte. Dichos efectos sobre el medio ambiente comprenden los que afectan a la salud y la seguridad humanas, la flora, la fauna, el suelo, el aire, el agua, el clima, el paisaje y los monumentos históricos u otras estructuras fisicas, o a la interacción entre dichos factores; incluyen asimismo los efectos sobre el patrimonio cultural o las condiciones socioeconómicas resultantes de la alteración de estos factores."

El lenguaje empleado pone de manifiesto que el Convenio del Agua busca prevenir tanto el daño a un curso de agua derivado de actividades que pueden tener lugar fuera del curso de agua en sí mismo -siempre que exista un vínculo entre el ecosistema del agua y el del ambiente afectado o en el cual se haya desarrollado la actividad que causó el daño-, como el daño causado por usos del curso de agua, a elementos del medio ambiente distintos del agua. En particular, se destaca que la última oración del numeral 2 del artículo 2 citado comprende incluso la salud y la seguridad humanas, la flora, la fauna, el suelo, el aire, el agua, el clima, el paisaje, los monumentos históricos u otras estructuras físicas, el patrimonio cultural y las condiciones socioeconómicas.

Por otro lado, y de forma concluyente, cuando se menciona la necesidad de cooperación, el Convenio en su artículo 9 sobre “Cooperación bilateral y multilateral”establece que: "1. Las Partes Ribereñas, (. . .) especificarán cuál es la cuenca hidrográfica, o su parte o partes, que serán objeto de cooperación. Esos acuerdos o arreglos se referirán a las cuestiones pertinentes contempladas en el presente Convenio, así como a cualquier otro asunto con respecto al cual las Partes Ribereñas consideren necesario cooperar."

Entendemos por todo lo visto que el enfoque de la Convención de 1997 es claramente más restrictivo que el del Convenio del Agua de 1992, y que este último está más en línea con un enfoque ecosistémico y basado en el concepto de cuenca. Esta interpretación es confirmada por la UNECE en su "Guía para la Implementación del Convenio sobre el Agua", que en su párrafo 84 expresa: "El Convenio sobre el Agua es aplicable a cualquier actividad que pueda causar un impacto transfronterizo sin que se defina la naturaleza y localización de dicha actividad. Eso significa que una actividad que cause o pueda causar impactos transfronterizos puede tener lugar en cualquier parte del territorio de un Estado, sin tener en cuenta su proximidad a la frontera o al cuerpo de agua. Por consiguiente, los Estados deberán considerar la totalidad de la cuenca hidrológica, e incluso, en algunos casos aún más allá (en acuíferos confinados, por ejemplo, la totalidad de las áreas de recarga) para garantizar que no haya lugar a ningún impacto transfronterizo."

\subsection{Material}

En lo que se refiere al ámbito material de aplicación, el Convenio del Agua está dirigido a regular todo esfuerzo que permita fomentar y "reforzar la cooperación, a nivel bilateral y multilateral, para la prevención, el control y la reducción de la contaminación transfronteriza, para la gestión sostenible de las aguas, para la conservación de los recursos hidricos y para la protección del medio ambiente". ${ }^{9}$ Siendo el objeto del Convenio

${ }^{8}$ UNECE, Guía para la Implementación del Convenio sobre el Agua, 2014, Disponible en: https:// www.unece.org/es/environmental-policy/conventions/water/envwaterpublicationspub/.

${ }^{9}$ Preámbulo, Párrafo 4. Mismos términos: "prevenir, controlar y reducir" son utilizados en otros párrafos preambulares y en las normas del Convenio. 
la prevención, control y reducción del impacto transfronterizo, tal y como se define en el artículo 1, párrafo 2, entendemos que el alcance de la aplicación material del Convenio del Agua es de mayor amplitud que la Convención de 1997.

En efecto, la definición del ámbito material en la Convención de 1997 pasa por la determinación de cuáles usos del agua que están incluidos..$^{10}$ Ese tema no es relevante en el caso del Convenio del Agua, donde en cambio adquiere mucha mayor trascendencia a los efectos de definir el ámbito de aplicación material la concepción ecosistémica del acuerdo que en definitiva hace caer dentro de su ámbito de aplicación material toda actividad humana con impacto transfronterizo. ${ }^{11}$

En puridad, esto nos indica que el Convenio del Agua, a diferencia de la Convención de 1997, es mucho más un acuerdo que se preocupa por regular los aspectos relacionados con la protección ambiental pudiendo entrar en esa categoría de acuerdos sin dificultades, lo cual implica una diferencia de naturaleza entre ambos, pese a su indudable similitud normativa.

\section{PRINCIPIOS GENERALES INCLUÍDOS EN EL CONVENIO.}

El Convenio del Agua incluye en su normativa la regulación de los tres principios fundamentales en materia de cursos de agua internacionales: a saber, la obligación de no causar daño, el principio de uso y participación equitativa y razonable, y el principio de cooperación. No obstante, como veremos a continuación, existen algunas diferencias en cuanto al manejo de los tres principios con respecto a la Convención de 1997, cosa que ha generado debate sobre si ambos instrumentos son compatibles, a lo cual intentaremos dar respuesta a lo largo de este apartado.

\subsection{Obligación de no causar daño}

La principal obligación general que contiene el Convenio del Agua está establecida en su artículo 2, ya citado, por el cual las Partes se comprometen a adoptar todas las medidas adecuadas para prevenir, controlar y reducir todo impacto transfronterizo. Esta disposición se traduce en la obligación de no causar daño (relevante).

El Convenio del Agua, al igual que la Convención de 1997, determina cual es el umbral de daño que debe considerarse (el relevante), en los conceptos de "daño significativo" o de "efecto adverso importante". En ambos instrumentos, se utilizan estos conceptos que son abstractos y propios de acuerdos de carácter general como los que estamos examinando, los cuales brindan una norma simplemente de orientación para la determinación del umbral de daño aceptable. En este sentido, los dos tratados coinciden en adoptar un lenguaje del cual se deduce que no cualquier nivel de daño es considerado relevante, sino sólo el que es de naturaleza significativa.

Así, la obligación de no causar daño en el Convenio del Agua se basa, al igual que en la Convención de 1997, en una obligación de diligencia debida-en contraposición a las

\footnotetext{
${ }^{10}$ Artículo 1 de la Convención de 1997.

${ }^{11}$ Artículo 2 del Convenio del Agua:"Las Partes adoptarán todas las medidas apropiadas para prevenir, controlar y reducir todo impacto transfronterizo."
} 
obligaciones absolutas- de "prevenir, controlar y reducir el impacto transfronterizo significativo" (artículo 2), para lo cual las partes deben tomar "todas las medidas apropiadas "y por la cual se incurre -incluso habiendo tomado "todas las medidas apropiadas"-, en la obligación adicional de controlar y reducir los efectos del impacto sufrido por el otro Estado en caso de que sucediera. En este sentido, ambos instrumentos entienden que la obligación de diligencia debida de tomar "todas las medidas apropiadas" se aplica no sólo a la obligación de prevención, sino también a la de control y reducción del daño o impacto transfronterizo posterior.

Ahora bien, existe un grado importante de relatividad en el concepto de "diligencia debida" a la hora de definir el contenido y los plazos en que las partes deben tomar esas "medidas apropiadas" y, mientras que la Convención de 1997 no brinda mayores elementos al respecto, el Convenio sobre el Agua sí lo hace, complementando (y en cierta forma ampliando) a la primera. Por ello, ciertos autores ${ }^{12}$ señalan que la obligación de diligencia debida -que está formulada en términos abstractos en la Convención de 1997-, debe ser implementada a la luz de los principios orientadores específicos contenidos en el Convenio del Agua, con especial consideración a estándares ecológicos consistentes en "las mejores tecnologías disponibles", las "mejores prácticas ambientales", la "evolución ambiental previa" y el "principio de precaución".

En efecto el párrafo 5 del artículo 2 del Convenio establece algunos principios generales "novedosos" que deben inspirar las medidas adoptadas por los Estados Partes entre los cuales se encuentra -entre otros- el principio de precaución:

“a) El principio de precaución, en virtud del cual no se pospondrán las actuaciones encaminadas a evitar el posible impacto transfronterizo de la emisión de sustancias peligrosas so pretexto de que los trabajos de investigación científica no han demostrado plenamente la existencia de una relación causal entre dichas sustancias, por un lado, y un eventual impacto transfronterizo, por el otro;

b) El principio de que quien contamina paga, en virtud del cual los costos de las medidas de prevención, control y reducción de la contaminación correrán a cargo del contaminador;

c) Los recursos hídricos se gestionarán de modo que las necesidades de la generación actual se atiendan sin poner en peligro la capacidad de las generaciones futuras para satisfacer sus propias necesidades."

Nosotros pensamos, a diferencia de la tesis mencionada anteriormente, que la introducción de los principios referidos en los literales a) y b) de este artículo 5, propios del derecho ambiental, no tienen correlación directa en la Convención de $1997^{13}$ y resulta demasiado forzado el pretender incluir a estos principios como "orientadores" de la interpretación de dicha Convención.

Si bien estos tratados deben intentar complementarse, y, de acuerdo al principio de armonización, cuando varias normas tratan de la misma cuestión, esas normas deben

${ }^{12}$ TANZI, Attila, Op.cit.,Pág. 6.

${ }^{13}$ La referencia del literal (c), en cambio, sí podría enmarcarse dentro del principio de utilización equitativa y razonable. 
interpretarse, en la medida de lo posible, de modo que den lugar a una sola serie de obligaciones compatibles, ${ }^{14}$ tampoco se le puede hacer decir a uno lo que no dice.

En este sentido podemos agregar que la integración del principio precautorio en temas ambientales relacionados con un curso de agua no fue de recibo hasta ahora por la Corte Internacional de Justicia (CIJ), por lo cual mal lo podríamos considerar, además, un principio consuetudinario en la materia, que nos ayudara en una interpretación tan audaz. De haber sido así, la sentencia en el asunto relativo a las plantas de celulosa entre Argentina y Uruguay hubiera sido favorable a la Argentina, que solicitaba a la Corte la aplicación de dicho principio, pero que no tuvo éxito en su petición, siendo esto esencial para el resultado adverso a sus intereses en el fallo. ${ }^{15}$ Pero es justo decir que esto no lo podía saber el Prof. Tanzi en el año en que escribió el artículo de referencia mencionado (año 2000) ni los autores que entonces cita en su nota al pie veintinueve. ${ }^{16}$

Por este motivo consideramos que esta inclusión del principio precautorio es una diferencia esencial entre ambas Convenciones que no ha sido debidamente resaltada por la doctrina, que pasa por alto esta diferencia a nuestro juicio esencial.

En el mismo sentido, pero dicho solamente en relación a los signatarios del Convenio del Agua -lo cual la exime de los comentarios previos- la Guía para la implementación del Convenio sobre el Agua ratifica que:

"La relatividad y la flexibilidad de la obligación de adoptar "medidas apropiadas" se complementa, en virtud del Convenio, con principios generales como el principio de precaución, el principio de "el que contamina paga» y el principio de sostenibilidad (artículo 2, párrafo 5), y normas como las que se recogen en el artículo 3, que prevén tanto el establecimiento de un régimen de autorizaciones basado en la mejor tecnología disponible y la evaluación del impacto medioambiental, como el establecimiento de límites de emisión y de criterios de calidad del agua, entre otros. Esas normas y principios contribuyen a la determinación concreta del contenido normativo de las obligaciones de diligencia debida en la prevención y del correspondiente deber de cuidado."17

Finalmente, entendemos que para las Partes del Convenio del Agua se aplican por cierto los párrafos 3 y 4 de su artículo 2, que establecen que todas las acciones cuyo objetivo sea luchar contra la contaminación del agua se tomarán en el origen de la contaminación, y que las medidas adoptadas no deberán ocasionar, como resultado directo ni indirecto, una transferencia de dicha contaminación a otros medios. Esta precisión, en estos términos, no está prevista en la Convención de 1997.

También cabe destacar que el artículo 3 del Convenio del Agua, referido a la prevención, control y reducción de la contaminación, establece que las medidas para reducir el impacto

\footnotetext{
${ }^{14} \mathrm{CDI}$, Informe sobre Fragmentación del Derecho Internacional, disponible en:http://legal.un.org/ilc/ reports/2006/spanish/chp12.pdf. consultado el 20/08/18

15 VATNA, Loïc, L'Affaire Usines des Pâtes à Papier sur le Fleuve Uruguay (Argentine c/ Uruguay) : un Nouveau Différent Environnemental devant la Cour Internationale de Justice, En: Revue Québécoise de Droit International, Vol. 22, N², 2009, Pág. 45, Disponible en:www.sqdi.org/wp-content/ uploads/22_2_Vatna.pdf. consultado el 29/08/18

16 TANZI, Attila, Op.cit.,Pág 11.

${ }^{17}$ UNECE, Guía para..., Op.cit., Págs. 11 y 12.
} 
transfronterizo serán de carácter jurídico, administrativo, económico, técnico y financiero. Las Partes podrán adoptar criterios de calidad del agua o definir límites de emisión para los vertidos en las aguas de superficie. Este tipo de contaminación podrá evitarse o reducirse gracias a la utilización de técnicas poco contaminantes (artículo 3, párrafo. 2). Todo esto sí parece constituir un desarrollo interpretativo natural y aceptable de las disposiciones generales de la Convención de 1997 al respecto, establecidas en su Parte IV.

\subsection{El principio de uso equitativo y razonable.}

El principio está formulado en el artículo 2, párrafo 2@ y 5đ. Su ubicación parece sorpresiva, pues integra el artículo sobre la obligación de no causar daño, y no constituye como en la Convención de 1997 un artículo diferenciado.

Pese a ello, por la forma en que se introduce el mismo, no parece querer significar una prevalencia del principio de no causar daño sobre el del uso equitativo y razonable, sino una aplicación del primero en consonancia con el segundo. En efecto, el artículo referido menciona que:

"2. Las Partes tomarán, en particular, todas las medidas necesarias paraL...) c) Garantizar que las aguas transfronterizas se utilicen de forma razonable y equitativa, teniendo en cuenta especialmente su carácter transfronterizo, en el caso de actividades que causen o puedan causar un impacto transfronterizo.

\section{(...)}

5. Al tomar las medidas mencionadas en los apartados 1 y 2 del presente artículo las Partes se regirán por los principios siguientesL...) c) Los recursos hídricos se ordenarán de forma que se satisfagan las necesidades de la generación actual, sin comprometer la capacidad de las generaciones futuras para satisfacer sus propias necesidades (...)"

La enunciación del principio es compatible con la de la Convención de 1997, y se encuentra "plenamente en consonancia con el desarrollo contemporáneo del derecho internacional consuetudinario del agua, según el cual el principio de la utilización equitativa incorpora el del desarrollo sostenible. Es decir, el uso de un cuerpo de agua internacional no puede ser considerado como equitativo, por lo tanto legal, si no es sostenible."18

La compatibilidad se refuerza en este caso por la formulación abstracta del principio, propia de instrumentos de naturaleza marco, como los que estamos examinando, que para su aplicación concreta a un curso de agua o cuenca específica, requerirán de una evaluación de la naturaleza equitativa de un uso ya existente o planificado.

Por lo demás, en el esquema de ambos instrumentos, la cooperación es requisito ineludible para la aplicación práctica del principio, ya que es ella la que permitirá realizar una evaluación caso por caso. En el caso del Convenio del Agua, como veremos más adelante, se hará de conformidad con sus normas, que prevén el intercambio mutuo de información y datos sobre esos factores específicos de la cuenca y del país, así como el desarrollo de consultas.

${ }^{18}$ UNECE, Guía para ..., Op.cit., Párrafo 102. 
La Convención de 1997, por su parte, contiene orientaciones más específicas, pero que pueden considerarse complementarias con las disposiciones del Convenio del Agua. Por ejemplo, en el artículo 6, titulado "Factores pertinentes para una utilización equitativa y razonable" la Convención ofrece, en el párrafo 1, una guía útil para la identificación de factores y circunstancias que se deben tener en cuenta al ponderar intereses de los Estados ribereños de cada curso de agua, pertinentes en el intercambio de datos e información y en las consultas. Estos factores se relacionan con las características físicas de los recursos, la población dependiente de las aguas, los usos actuales y potenciales, el impacto de estos usos y la disponibilidad de usos alternativos o de la adopción de prácticas más eficientes.

Otro tema en el cual la Convención de 1997 avanza un poco más, brindando una orientación más concreta para la aplicación de este principio, es el caso del artículo 10, párrafo 2 , que establece que se ha de prestar especial atención a las necesidades humanas vitales. En este sentido, si bien ningún uso o categoría de usos tiene en sí prioridad frente a los demás, el criterio da una pauta concreta para resolver conflictos entre diversos usos de agua. ${ }^{19}$

Nuevamente, estaríamos ante un caso de complementariedad de ambos instrumentos, y no de contradicción entre los mismos.

\subsection{El principio de cooperación.}

El preámbulo del Convenio del Agua anticipa el rol central que cumplirá la cooperación, y en particular la cooperación institucional, en la implementación de su regulación, al subrayar que "la cooperación entre los países miembros en materia de protección y utilización de las aguas transfronterizas se efectuará principalmente mediante la elaboración de acuerdos entre países ribereños de las mismas aguas, en particular cuando tales acuerdos no existan todavía." ${ }^{20}$

El principio de cooperación está establecido como principio general en el artículo 2 párrafo 6, que indica:

"Las Partes Ribereñas cooperarán sobre la base de la igualdad y la reciprocidad, en particular mediante acuerdos bilaterales y multilaterales, con el fin de elaborar políticas, estrategias y programas armonizados, aplicables a la totalidad o a parte de las cuencas hidrográficas pertinentes y destinados a prevenir, controlar $y$ reducir el impacto transfronterizo y a proteger el entorno de las aguas transfronterizas o el entorno sobre el que estas influyan, incluido el medio marino"

Como puede apreciarse de la lectura de este artículo, la cooperación institucional entre las partes ribereñas es de carácter obligatorio en el Convenio del Agua. Esta es una

${ }^{19}$ La «declaración de entendimiento» que se basa en el comentario de la CDI y acompaña el texto de la Convención, indica que: "en la determinación de la "necesidad vital humana” se ha de prestar atención especial al suministro suficiente de agua para sostener la vida humana, incluidas el agua potable y el agua necesaria para la producción de alimentos a fin de prevenir la hambruna". En última instancia, al sopesar todos los factores pertinentes, se debe hacer todo lo posible para maximizar equitativamente los beneficios de los Estados del curso de agua, protegiendo al mismo tiempo la sostenibilidad a largo plazo del recurso.

20 Último párrafo del preámbulo. 
diferencia bien clara respecto de la Convención de 1997, en la cual este tipo de cooperación, si bien está recomendada, no es obligatoria.

En cambio, los objetivos del Convenio del Agua se logran mediante un "enfoque de doble nivel" que contempla dos categorías de obligaciones principales. En la parte I se incluyen las obligaciones generales y en la parte II obligaciones más específicas, que se tienen que implementar a través de la celebración de acuerdos entre las partes ribereñas que compartan las mismas aguas transfronterizas:

\section{“Artículo 9 Cooperación bilateral y multilateral}

1. Las Partes Ribereñas, ateniéndose a los principios de igualdad y reciprocidad, concertarán acuerdos bilaterales o multilaterales o arreglos de otra índole, cuando no los haya, o adaptarán los existentes, cuando ello sea necesario para eliminar las contradicciones con los principios fundamentales del presente Convenio, con la finalidad de definir sus relaciones mutuas y su conducta en lo que atañe a la prevención, el control y la reducción del impacto transfronterizo. Las Partes Ribereñas especificarán cuál es la cuenca hidrográfica, o su parte o partes, que serán objeto de cooperación. Esos acuerdos o arreglos se referirán a las cuestiones pertinentes contempladas en el presente Convenio, así como a cualquier otro asunto con respecto al cual las Partes Ribereñas consideren necesario cooperar."

Además de esta obligación de concertar acuerdos específicos, el artículo 9 añade la obligación de establecer órganos conjuntos, ${ }^{21}$ y otros artículos añaden obligaciones de realizar consultas, ${ }^{22}$ poner en práctica programas conjuntos de vigilancia del estado de las aguas transfronterizas y de evaluación del estado de las aguas, ${ }^{23}$ intercambiar información, ${ }^{24}$ realizar actividades específicas de investigación y desarrollo, ${ }^{25}$ prestarse ayuda mutua previa solicitud, ${ }^{26}$ etc.

También añade algo a nuestro juicio esencial, cuando establece en el mismo artículo 9 la obligación de adaptar los acuerdos de cursos de agua "a los principios fundamentales del presente Convenio". Naturalmente que no existe tal requerimiento en la Convención de $1997,{ }^{27}$ y nos parece de gran importancia por la inclusión en este Convenio del principio precautorio que es un principio del derecho ambiental que no existe en la Convención de 1997 y que a nuestro juicio es la gran diferencia y razón por la cual muchos Estados no habrán de adherirse a este Convenio del Agua.

Más allá de esto, queda claro que en el Convenio del Agua el principio de cooperación tiene un vasto ámbito de aplicación, que se extiende a todo el conjunto de políticas, programas y estrategias necesarias para la consecución de los objetivos del Convenio y que

${ }^{21}$ Artículo 9, parágrafo 2.

22 Artículo 10.

23 Artículo 11.

${ }^{24}$ Artículo 13. Cabe señalar que, mientras el Convenio del Agua permite limitar el intercambio de información entre las Partes Ribereñas en base a los derechos de propiedad intelectual, la Convención de 1997 no permite tal limitación.

25 Artículo 12.

${ }^{26}$ Artículo 15.

27 UNECE, Apertura Global del Convenio del Agua de 1992, Op.cit. 
se sostiene, como veremos en el punto siguiente, en un mecanismo institucional de cooperación que constituye en sí mismo una plataforma intergubernamental para el desarrollo de la cooperación transfronteriza en las actividades cotidianas.

\section{NORMAS INSTITUCIONALES}

Un valor añadido del Convenio del Agua destacado por la doctrina y la propia UNECE, ${ }^{28}$ está referido, por un lado, al marco institucional que se establece con el fin de ayudar a las Partes en el cumplimiento de sus disposiciones y en su ulterior desarrollo; y, por otro lado, en el carácter obligatorio de la cooperación institucional entre las Partes ribereñas. Ninguna de estas características está presente en la Convención de 1997.

A la obligación de concertar acuerdos señalada supra, se suma la de establecer órganos conjuntos para las aguas compartidas entre Estados ribereños. La Convención de 1997 se limita a recomendar a los Estados del curso de agua a cooperar a través de órganos conjuntos, y quizás por este motivo es más extensa en detallar las obligaciones procedimentales de consulta y notificación.

En cambio, el artículo 9.2 del Convenio establece:

"Los acuerdos o arreglos mencionados en el párrafo 1 del presente artículo dispondrán el establecimiento de órganos conjuntos. Las funciones de estos órganos conjuntos serán, entre otras, y sin perjuicio de lo dispuesto en los acuerdos o arreglos pertinentes que ya existan, las que figuran a continuación:

a) Reunir, recopilar y evaluar datos con el fin de determinar cuáles son las fuentes de contaminación que con probabilidad puedan producir un impacto transfronterizo;

b) Elaborar programas de vigilancia conjunta relativos a la cantidad y calidad del agua;

c) Hacer inventarios e intercambiar información sobre las fuentes de contaminación mencionadas en el párrafo 2 a) del presente artículo;

d) Establecer límites de emisión para las aguas residuales y evaluar la eficacia de los programas de control;

e) Definir objetivos y criterios conjuntos de calidad del agua teniendo en cuenta lo dispuesto en el artículo 3, párrafo 3, del presente Convenio, y proponer las medidas que correspondan para mantener $y$, cuando sea necesario, mejorar la calidad del agua;

f) Elaborar programas de acción concertada para la reducción de las cargas de contaminación procedentes tanto de fuentes puntuales (por ejemplo, las fuentes urbanas e industriales) como de fuentes difusas (en particular las agrícolas);

g) Establecer procedimientos de aviso y alerta;

h) Servir de foro para el intercambio de información sobre los usos existentes y previstos del agua y las instalaciones conexas que con probabilidad podrían causar un impacto transfronterizo;

${ }^{28}$ UNECE, Guía para la Implementación..., Op.cit. 
i) Promover la cooperación y el intercambio de información sobre la mejor tecnología disponible con arreglo a lo dispuesto en el artículo 13 del presente Convenio, y fomentar la cooperación en programas de investigación científica;

j) Participar en la realización de evaluaciones del impacto ambiental de las aguas transfronterizas, de conformidad con la normativa internacional pertinente. (...)"

Adicionalmente, el Convenio del Agua de 1992 establece un mecanismo institucional basado en la Reunión de las Partes, que no tiene equivalente en la Convención de 1997. El artículo 17 regula la Reunión de las Partes de la siguiente manera:

"1. La primera reunión de las Partes se celebrará a más tardar un año después de la fecha de entrada en vigor del presente Convenio. Posteriormente, se celebrarán reuniones ordinarias cada tres años o a intervalos más cortos, según se establezca en el reglamento.

Las Partes celebrarán una reunión extraordinaria si asílo deciden en una reunión ordinaria o si una Parte lo solicita por escrito, a condición de que dicha solicitud haya sido respaldada por al menos un tercio de las Partes en los seis meses siguientes a su comunicación a todas las Partes.

2. En las reuniones, las Partes someterán a evaluación continua la aplicación del presente Convenio, y con este objetivo en mente:

a) Examinarán las políticas y los enfoques metodológicos empleados para la protección y la utilización de las aguas transfronterizas de las Partes con vistas a seguir mejorando la protección y la utilización de dichas aguas;

b) Intercambiarán información sobre la experiencia adquirida en la celebración y aplicación de acuerdos bilaterales y multilaterales o arreglos de otra índole relativos a la protección y la utilización de las aguas transfronterizas en los que sean parte una o varias de las Partes;

c) Solicitarán, cuando proceda, los servicios de los órganos correspondientes de la Comisión Económica para Europa, así como de otros comités específicos y organismos del ámbito internacional que sean competentes, para todas las cuestiones relacionadas con el logro de los objetivos del presente Convenio;

d) En su primera reunión, estudiarán y aprobarán por consenso el reglamento de las reuniones;

e) Estudiarán y aprobarán las propuestas de enmienda al presente Convenio;

f) Estudiarán y emprenderán cualquier otra medida que pueda ser necesaria para alcanzar los objetivos del presente Convenio."

Cada una de las partes en el Convenio tiene un voto, salvo el caso en que voten como organización regional de integración económica (en los asuntos de su competencia), en cuyo caso ésta tiene un número de votos igual al número de sus Estados miembros Partes en el Convenio. ${ }^{29}$ La Secretaría del Convenio es llevada por el Secretario Ejecutivo de la UNECE Económica. ${ }^{30}$

${ }^{29}$ Según el artículo 18, Esas organizaciones no ejercerán su derecho de voto si sus Estados miembros ejercen el suyo, y viceversa.

${ }^{30}$ Artículo 19. 


\section{SOLUCIÓN DE DIFERENCIAS.}

El artículo 22 del Convenio del Agua establece el método de solución de controversias, en el caso que se suscitara entre algunos de los Estados Partes.

En primer lugar, de sobrevenir una disputa entre dos o más Estados Partes sobre la interpretación o aplicación del Convenio, éstas buscarán resolver el conflicto a través de la negociación o cualquier otro medio aceptable. ${ }^{31}$ Pero luego los párrafos 2 y 3 del mismo artículo 22 establecen la posibilidad-mediando su previo consentimiento escrito-de acceder a otros medios:

"2. En el momento de la firma, ratificación, aceptación o aprobación del presente Convenio, o de la adhesión a él, o en cualquier momento posterior, las Partes podrán comunicar por escrito al Depositario que, en relación con una controversia que no se resuelva conforme a lo dispuesto en el párrafo 1 del presente artículo, aceptan la obligatoriedad de uno de los dos medios siguientes, o de ambos, para la solución de controversias con aquellas Partes que hayan aceptado la misma obligación:

a) La presentación de la controversia a la Corte Internacional de Justicia;

b) El arbitraje con arreglo al procedimiento establecido en el anexo IV.

3. Si las partes en la controversia han aceptado los dos medios para la solución de controversias previstos en el párrafo 2 del presente artículo, la controversia se someterá únicamente a la Corte Internacional de Justicia, salvo que las partes convengan en otra cosa."

Esta solución es diferente a la de la Convención de 1997, ya que esta prevé el establecimiento de una Comisión de Determinación de los Hechos que hará recomendaciones a las Partes, ${ }^{32}$ sin impedirles por supuesto utilizar todos los demás medios para solucionar su conflicto que, esos sí, prevé el Convenio, pero sin predeterminarlos de la forma en que lo hace el Convenio.

\section{CONCLUSIONES}

\section{a) Ambos textos son complementarios. Ratificación de principios consuetudi- narios.}

En principio, es un hecho que las diferencias que se han señalado entre ambos instrumentos no impiden que Estados partes de ambos instrumentos los implementen al mismo tiempo. Las diferencias deben ser por tanto conciliadas y así ha sido el enfoque adoptado en la UNECE, que entiende que ser Parte en ambos Convenios permite al país

31 Artículo 22(1).

32 Artículo 33(4) de la Convención de 1997.

${ }^{33}$ El Secretario General de las Naciones Unidas, así como muchos países y organizaciones, hicieron ya un llamamiento a favor del establecimiento de las sinergias en la implementación de los dos Convenios. La Reunión de las Partes del Convenio del Agua, en su Sexta sesión del 28 al 30 de noviembre de 2012, ha decidido promover las sinergias y coordinación con la Convención de cursos de agua de 1997 a través de un intercambio de experiencias acumuladas en el marco del Convenio del Agua a fin de apoyar la 
beneficiarse de sus marcos legales sólidos, así como fomentar el desarrollo y la aplicación del derecho internacional de aguas, reforzando el rol de este derecho a nivel global. ${ }^{33}$

Creemos que efectivamente la regulación del Convenio del Agua es en la mayoría de los aspectos conciliable la Convención de 1997, no existiendo contradicciones notorias entre ellos, motivo por el cual seguramente varios países han accedido a firmar ambos tratados. ${ }^{34}$

En esta visión optimista, cabe citar al respecto lo expresado por la Comisión Económica para Europa de las Naciones Unidas, en su publicación “Apertura Global del Convenio del Agua de 1992":

"La Convención de Cursos de Agua de 1997 complementa el Convenio del Agua de 1992, detallando los factores relativos al uso equitativo y razonable (art. 6 de la Convención de Cursos de Agua de 1997), facilitando los trámites para las consultas sobre medidas planificadas (Parte III de la Convención de Cursos de Agua de 1997) y describiendo las consecuencias de la incidencia del impacto transfronterizo (art. 7(2) de la Convención de Cursos de Agua de 1997). Por otro lado, el Convenio del Agua de 1992 complementa la Convención de Cursos de Agua de 1997, prescribiendo el contenido de acuerdos específicos y de tareas de órganos conjuntos (art. 9 del Convenio del Agua de 1992), detallando la información, sujeto a la evaluación e intercambio conjuntos (arts. 11 y 13 del Convenio del Agua de 1992) así como ofreciendo directrices detalladas sobre los objetivos de calidad de agua y la mejor tecnología disponible (anexos al Convenio del Agua de 1992)."

Además de esta complementariedad, que los especialistas se esfuerzan en remarcar para evitar situaciones de conflicto o competencia entre ambos textos, la reiteración y la formulación dada en ambas convenciones de algunos principios como la utilización equitativa y razonable, la obligación de no causar daño y la cooperación, no hacen sino confirmar un aspecto importante, que es su carácter de normas consuetudinarias.

\section{b) Ambos textos tienen sin embargo diferencias en puntos sustanciales.}

Sin embargo, hemos señalado algunas diferencias que no son sólo desarrollos puntuales, sino diferencia reales, como es el tema de los acuíferos confinados, de la limitación de información por razones de propiedad intelectual en el Convenio, de la noción de cuenca, opuesta a la de curso de agua, así como las obligaciones institucionales previstas en el Convenio en el sentido de adoptar acuerdos, y, esencialmente, la obligación en el Convenio de adaptarlos de acuerdo a sus principios básicos, lo cual hace entrar en juego una aplicación del principio precautorio.

También las disposiciones de cada tratado (art 9(1) del Convenio y 3(1) de la Convención) prevén la compatibilidad de cada uno de ellos con los demás tratados específicos que se celebren sobre el tema, lo cual aplica en la relación entre ellos ${ }^{35}$ y con otros tratados

implementación de la Convención de cursos de agua de 1997, promoviendo los intercambios y coordinación entre las Partes en los dos Convenios y ofreciendo un marco intergubernamental para debate sobre los dos Convenios.

${ }^{34}$ De hecho, muchos lo son: Alemania, Chad, Dinamarca, España, Finlandia, Grecia, Hungría, Italia, Luxemburgo, Noruega, Países Bajos, Portugal, Suecia y Uzbekistán. Fuente: UNECE, Apertura Global del Convenio del Agua de 1992, Op.cit., Pág. 14, consultada el 25 de julio de 2017.

${ }^{35}$ A suponer que uno pueda ser considerado específico respecto del otro (ver punto siguiente). 
bilaterales que se puedan suscribir o que existan, con las salvedades de lo dicho en el párrafo anterior sobre las obligaciones que prevé el Convenio del Agua en materia institucional y de adaptación de acuerdos existentes. Estas últimas son de naturaleza suficientemente significativa para que se puedan generar conflictos normativos con la aplicación simultánea de este Convenio y la Convención de 1997, y mucho más aún con otros acuerdos bilaterales existentes o que se celebren sobre un curso de agua.

\section{c) Complejidad de la aplicación de las normas si entran en conflicto.}

En cuanto a su aplicación simultánea, estamos ante dos tratados internacionales y en caso de que exista contradicción entre ambos instrumentos -para aquellos Estados que hayan suscrito ambos textos- se deberán aplicar al respecto las disposiciones previstas a tales efectos en los artículos 30 y 59 de la Convención de Viena sobre el Derecho de los Tratados entre Estados. Y, en esta medida, el principio de que la ley especial deroga a la ley general, o la posterior a la anterior, así como la libertad de las partes para determinar sus obligaciones en casos de superposición de normas diferentes en el mismo tema, si la hubiere.

Cada situación se deberá adaptar a las circunstancias propias del caso y en esa medida además, determinar el sistema de solución de controversias al que recurrir en función del conflicto, lo que puede ser una nueva fuente de conflicto. Será obviamente necesario determinar cuál de los dos textos es general o es especial respecto del otro, lo cual no parece sencillo. En materia de especialidad ambos aparecen como tratados generales, en cuyo caso habría que atenerse mayoritariamente a aplicar el último en el tiempo, pero no faltará quién encuentre rasgos de especialidad ambiental o de otro tipo en alguno de los textos para aplicarlo en su favor. En este sentido, el Convenio del Agua parece contener mayor cantidad de regulaciones más precisas en algunas cosas que lo convertirán en más específico para quienes han suscrito ambos acuerdos. Por lo pronto no es frecuente la existencia de dos convenios marco que regulen un mismo tema, con muchas semejanzas y algunas diferencias.

\section{d) Naturaleza jurídica}

Por último, pero no por ello menos importante, nos parece bien claro que el Convenio del Agua es un tratado que puede considerarse de Derecho Ambiental, con énfasis en los cursos de agua internacionales y sus cuencas, mientras la Convención de 1997 es un tratado solamente sobre los usos de los cursos de agua, con normas de protección ambiental incluidas básicamente para los mismos. De esta diferencia de naturaleza se producen distintos enfoques que se derivan en la mayoría de las diferencias puntuales a las que hemos aludido.

\section{BIBLIOGRAFÍA CONSULTADA}

BEAUGÉ, María Fabiana, "La necesidad de cooperación e integración en la protección de los acuíferos transfronterizos", en Cuadernos Política Exterior Argentina, Rosario octubre-diciembre $2010, \mathrm{~N}^{\circ} 102$.

BOISSON DE CHAZOURNES, L, "Fresh Water in International Law". Oxford. University Press, 2013. 
-KAZHDAN, Daniel, Precautionary Pulp: Pulp Mills and the Evolving Dispute between International Tribunals over the Reach of the Precautionary Principle, 38 Ecology L. Q, 527 (2001).

-VATNA, Loïc : "L'Affaire Usines des Pâtes à Papier sur le fleuve Uruguay (Argentine c/ Uruguay) : un nouveau différent environnemental devant la Cour Internationale de Justice" en Revue Québécoise de Droit International 22.2 (2009).

Mc CAFFREY, S, "The UN Convention on the Law of the Non-Navigational Uses of International Watercourses", Oxford University Press, Oxford, 2001.

SCHWEBEL, S, "El tercer informe sobre el derecho relativo a los usos de los cursos de agua a fines distintos que la navegación" Relator Especial en ACDI, 1982, II, $1^{\text {a }}$ parte.

TANZI, Attila, - "The Relationship between the 1992 UNECE Convention on the Protection and Use of Transboundary Watercourses and International Lakes and the 1997 UN Convention on the Law of the Non Navigational Uses of International Watercourses". Report of the UNECE Task Force on Legal and Administrative Aspects.

UNECE. "Apertura Global del Convenio del Agua de 1992", Comisión Económica para Europa de las Naciones Unidas

UNECE- "Guía para la Implementación del Convenio sobre el Agua", disponible en https:/www.unece.org/ es/environmental-policy/conventions/water/envwaterpublicationspub/envwaterpublicationspub74/ 2013/guide-to-implementing-the-water-convention/guia-para-la-implementacion-del-convenio-sobre-el-agua.html

VIÑUALES, J.E., La Protección Ambiental en el Derecho Consuetudinario Internacional, REDI, Vol. 69, (2017).

Decisiones Judiciales consultadas

-Corte Internacional de Justicia (CIJ) Asunto relativo al proyecto Gabçikovo-Nagymaros. 1997. Sentencia. Disponible en http://www.icj-cij.org/docket/files/92/7375.pdf

-CIJ, Asunto relativo a las plantas de celulosa sobre el río Uruguay, 2010, Sentencia. Disponible en http:/ /www.icj-cij.org/docket/files/135/15877.pdf. 
